\title{
38. Seven Tools of Operation Standardization for Mass Production of a New Product
}

\author{
Kosei Sugitani, Hiroshi Morita and Hiroaki Ishii \\ Department of Information and Physical Sciences, Osaka University, Japan \\ Email:[k-sugitani, morita, ishii]@ist.osaka-u.ac.jp
}

\begin{abstract}
We propose the effective tools of operation standardization for mass production of a new product. The cycle of operation standard consists of three stages of design, improvement and evaluation, and divided into seven steps, that is, decision, communication and understanding, observance, supervision, notice, decision again, and evaluation. The proposed seven tools of operation standardization (OS7) correspond to these steps. These tools enable us to realize mass production of a new product and to stabilize a product quality much earlier.
\end{abstract}

\section{INTRODUCTION}

Recently optical fiber communication services and devices have been wrestling with the problem of mass-production in the field of key material and devices. The key to dominant position in competition is the prompt supply of a product to customers with a steady production rate in quality. We often come across an important factor which brings great influences on a product quality. We should discover it and stabilize it in production line. It is important for us to standardize the operations.

The cycle of operation standardization consists of three stages of design, improvement and evaluation. Before the implementation of mass-production, we have defined the process of operation standardization as "design cycle". We have often implemented mass-production without clearly deciding an operation standard, which may have caused some serious quality problems. It is required to develop the effective tools for operation standardization to reduce these kinds of problems.

The process of operation standardization is divided into seven steps, that is, decision, communication and understanding, observance, supervision, notice, decision again, and evaluation. We propose the seven tools of operation standardization (OS7) corresponding to these steps to prevent the quality problems at the implementation of mass production of a new product. Table 1 summarizes the proposed OS7 together with the cycle and steps for operation standardization. We define the operation rank by using the color-coded card, and it enables us to communicate the information of operations with each other. OS7 is especially effective in the situation of mass production on which we can see dispersion of operations in a short term. 
There are many problems that we have to try to implement mass-production so far. To begin with, we consider the cycle of operation standardization as the cycle of decision, observance, decision again, and observance. We often used each of these steps separately and not systematically moreover. Secondly, we could not exactly catch up the information of the importance of operations such as dispersion of operations, effect on quality and so on, because there is no cycle of communication to operators and understanding of operators. As a result, it took us long time to stabilize the quality of a new product in mass production.

OS7 is shown in Table 1, each of which is denoted in the following section.

Table 1. The seven tools of operation standardization

\begin{tabular}{|l|l|l|}
\hline \multicolumn{1}{|c|}{ Cycle } & \multicolumn{1}{|c|}{ Method } & \multicolumn{1}{c|}{ Content } \\
\hline Design & S1: Decision & Decision of standard of elemental operations \\
\cline { 2 - 3 } & $\begin{array}{l}\text { S2: Communication } \\
\text { and understanding }\end{array}$ & $\begin{array}{l}\text { Analysis of the gap in recognition between } \\
\text { operators and technicians }\end{array}$ \\
\cline { 2 - 3 } & S3: Observance & $\begin{array}{l}\text { Analysis of the degree of observing operation } \\
\text { standard briefly in starting operation }\end{array}$ \\
\cline { 2 - 3 } & S4: Supervision & $\begin{array}{l}\text { Checking the percentages of observance } \\
\text { operation standard in operation }\end{array}$ \\
\hline Improvement & S5: Notice & $\begin{array}{l}\text { Extraction an operation know-how operator } \\
\text { detected in operation }\end{array}$ \\
\cline { 2 - 4 } & S6: Decision again & $\begin{array}{l}\text { Taking priority to standard of elemental } \\
\text { operations in worrying about quality problems }\end{array}$ \\
\hline Evaluation & S7: Evaluation & $\begin{array}{l}\text { Evaluation seven steps of operation } \\
\text { standardization }\end{array}$ \\
\hline
\end{tabular}

\section{SEVEN TOOLS OF OPERATION STADARDIZATION}

\subsection{S1: Tool for "Decision"}

Before implementing mass-production, we check the operations if there are any lacks of standardization that have influence on the production. In many cases, some operations are not standardized. If operator declines the reduction of production which is caused by violating the operation standard, we have to decide a new operation standard at once. $\mathrm{S} 1$ is the tool for decision of standard of elemental operations, and is used as follows.

- Confirm the flow of elemental operations composed of unit operation.

- Watch elemental operations of operators and estimate dispersion of quality optimistically and pessimistically.

- Consider operators' skill, we give priority to operations which will be dispersed and improve their standard of elemental operations.

- Check the effectiveness of improvement.

If we can grasp important operations which have influence on the production by using S1, operations dispersion will be decreased and quality will be stabilized in manufacturing process. After we decide the operation standard again, we have to inform it to all operators, including the information about important operations, such as dispersion of operations. 


\subsection{S2: Tool for "Communication and Understanding"}

We check the degree of understanding of operators so as to standardize each operation. We need to grasp the gap of recognition to each operation between operators and technicians. It is important to check the gap that may cause dispersion of quality. It could happen that some operators do not put emphasis on what technicians think important. Table 2 shows how to visualize the gap by using card. We have to make up for the gap using the card briefly. $\mathrm{S} 2$ is the tool for analysis of the gap in recognition between them, and is used as follows.

- Suppose a unit operation composed of some operations.

- Confirm the information of operation importance important have influence on the production.

- Confirm by handing to a technician the three cards, the A rank card, the B rank card, and the $C$ rank card, and let them select one of the cards. One operation is shown on one card. If a technician selects the A rank card which is red, he thinks that the operation is the most important one. Here we define the A rank card as the most important card which have influence on the production. $B$ rank card of which is yellow is less important than the A rank card, but operation of B rank is reasonably important. The $\mathrm{C}$ rank card which is blue is a normal operation where dispersing is acceptable.

- Let operators choose a card as we do to technicians.

We will be surprised at the difference of their chosen color-coded cards. An operator will show the $C$ rank card of the operation from his operation experience, even if technician shows the A rank card as to the same operation. The problem is that there are gaps of the recognition between operators and technicians. We have to solve this problem.

Table 2. Gap in recognition

\begin{tabular}{|l|l|l|l|}
\hline \multirow{2}{*}{ Elemental operation } & \multicolumn{2}{|c|}{ Recognition to operation } & \multirow{2}{*}{ Gap } \\
\cline { 2 - 3 } & Technician & Operator & \\
\hline Put two materials into the box & Red card & Yellow card & Yes \\
\hline Carry box & Blue card & Blue card & No \\
\hline Close box & Yellow card & Blue card & Yes \\
\hline
\end{tabular}

\subsection{S3: Tool for "Observance"}

The operators are informed the determined operation standard. So it is important to provide an appropriate operation environment to observe operation standard. We need to examine S3, the method of brief analysis of the degree of observing operation standard, from the viewpoint of prevention against occurrence and outflow. If we use S3 effectively, we can catch up the cause that operators have missed to observe the operation standard. S3 is used as follows.

- Check the degree of observing an operation standard from the point of occurrence prevention, and estimate it. (Table 3)

- Check the degree of observing an operation standard from the point of outflow prevention, and estimate it. (Table 4) The rank is determined according to the process capability index $\mathrm{Cp}$.

- Evaluate each elemental operation by using the rank of occurrence and outflow against prevention given in Table 3 and Table 4. (Table 5) 
- After finishing the total evaluation, we take measures against each high score greater than one with lower scores and confirm the effectiveness of theirs.

Table 3. The rank of occurrence against prevention

\begin{tabular}{|c|l|}
\hline Rank of occurrence against prevention & \multicolumn{1}{c|}{ Content } \\
\hline 1 & Equipped, Automatic \\
\hline 2 & Tooled \\
\hline 3 & Manual Inspected, Exist of Limit sample \\
\hline 4 & Exist of operation standard \\
\hline 5 & Exist of operation standard, No control \\
\hline
\end{tabular}

Table 4. The rank of outflow against prevention

\begin{tabular}{|c|l|}
\hline Rank of outflow against prevention & \multicolumn{1}{|c|}{ Content } \\
\hline 1 & Equipped, Automatic $(\mathrm{Cp}>1.33)$ \\
\hline 2 & Half Automatic $(\mathrm{Cp}>1.0)$ \\
\hline 3 & Control of a fixed quantity $(0.8<\mathrm{Cp}<1.0)$ \\
\hline 4 & Check, No record $(\mathrm{Cp}<0.8)$ \\
\hline 5 & No check \\
\hline
\end{tabular}

Table 5. The method of analysis of the degree of observing operation standard briefly in starting operation

\begin{tabular}{|c|c|c|c|c|c|c|}
\hline \multirow{2}{*}{$\begin{array}{l}\text { Element } \\
\text { operation } \\
\text { trouble }\end{array}$} & \multicolumn{2}{|c|}{$\begin{array}{l}\text { Occurrence } \\
\text { prevention }\end{array}$} & \multicolumn{2}{|c|}{$\begin{array}{l}\text { Outflow } \\
\text { prevention }\end{array}$} & \multirow{2}{*}{$\begin{array}{c}\text { Total } \\
\text { Evalua } \\
\text { tion }\end{array}$} & \multirow{2}{*}{ Goal } \\
\hline & & Rank & & Rank & & \\
\hline $\begin{array}{l}\text { More than three } \\
\text { materials }\end{array}$ & $\begin{array}{l}\text { Exist of one-point } \\
\text { standard }\end{array}$ & 3 & $\begin{array}{l}\text { Check } \\
\text { No record }\end{array}$ & 4 & $\bar{E}$ & $\mathrm{~A}$ \\
\hline $\begin{array}{l}\text { Short of } \\
\text { hydrochloric } \\
\text { acid }\end{array}$ & $\begin{array}{l}\text { Exist of standard } \\
\text { No control }\end{array}$ & 4 & No check & 5 & $\mathrm{~F}$ & $\bar{B}$ \\
\hline Open cover & No check & 5 & Warning & 2 & $\mathrm{E}$ & $\bar{A}$ \\
\hline
\end{tabular}

\subsection{S4: Tool for "Supervision"}

At the end of the design cycle, we confirm that operators observe the operation standard in manufacturing process. S4 is the tool for checking the percentages of observation of operation standard. If we find the operators who do not observe the operation standard, we give precedence to the A or B rank card. We inquire of the operator why it is difficult to observe the operation standard. Then it makes clear which step has a problem in the seven steps. S4 is used as follows.

- Make the sheet arranged in the elemental operations. (Table 6)

- Superintendents check mainly the percentages of observance of operation standard through observance of watching an operator operating in manufacturing line. And they estimate the point of each of elemental operations, writing check sheets.

- If they find the operator who does not observe the operation standard, they will ask him the reason. Sometimes, he may say that it is easy for him to maintain the operation standard because of his inexperienced skill. 
Table 6. The method of checking the percentages of observed operation standard

\begin{tabular}{|c|c|c|c|c|c|}
\hline \multirow{2}{*}{$\begin{array}{l}\text { Operation } \\
\text { point }\end{array}$} & \multirow{2}{*}{$\begin{array}{l}\text { Operation } \\
\text { content }\end{array}$} & \multirow{2}{*}{$\begin{array}{l}\text { Evalua } \\
\text { tion }\end{array}$} & \multicolumn{2}{|c|}{ Cause of not observation } & \multirow{2}{*}{$\begin{array}{l}\text { Measure } \\
\text { to meet }\end{array}$} \\
\hline & & & Factor & $\begin{array}{l}\text { Operation } \\
\text { standardization step }\end{array}$ & \\
\hline $\begin{array}{l}\text { Seize the } \\
\text { box }\end{array}$ & One time & $\mathrm{x}$ & $\begin{array}{l}\text { Use of old } \\
\text { operation standard }\end{array}$ & Communication & $\square$ \\
\hline $\begin{array}{l}\text { Put } \\
\text { powder } \\
\text { into box }\end{array}$ & Five times & $\triangle$ & $\begin{array}{l}\text { Not decided of } \\
\text { putting time into } \\
\text { box }\end{array}$ & Decision & $\square$ \\
\hline $\begin{array}{l}\text { Mix } \\
\text { powder }\end{array}$ & $\square$ & 0 & $\square$ & $\square$ & $\square$ \\
\hline
\end{tabular}

Next we define the improvement cycle inchuding notice and decision again step; the process we extract factors that cause quality problems by the elemental operations, and stabilize quality of product. We will decrease defects of the design cycle through this cycle by deciding operation standard again.

\subsection{S5: Tool for "Notice"}

In the improvement cycle, we will decide operation standard again to find remaining some important factors. We extract an operation know-how that is not stipulated in the operation standard and have influence on the production. We define the operation know-how that is found by operators and is not known to the technicians as the operation standard again. We will try to make the measures for each of the know-how, and confirm the effectiveness. If we will find out an important elemental operation, we define the rank of operation again, and append them to the operation standard. S5 is used as follows.

- Prepare the big size paper on the wall.

- We adopt the most important quality characteristic, and let operator paper cards written in the cause have influence on the production. In papering cards, operators distinguish the A or B rank card from the C rank it. (See Figure 1.) After papering the cards, we give a priority to the card to make measures from the technical viewpoint.

- Add a useful know-how which will be effective to operation standard in it.

- Confirm the effectiveness of it by time series analysis.

Notice that S5 resembles to cause and effect diagram, but the difference is that the operator uses the color-coded cards and confirms the effectiveness by time series analysis.

C rank card

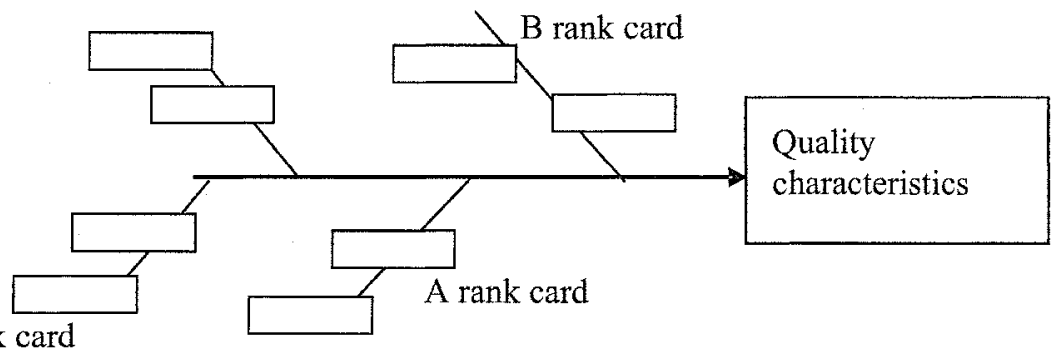

Figure 1. Extraction of an operation know-how detected in operation by operators 
We have had experienced in meeting with the quality problems caused by that the operators do not observe the operation standard before starting mass-production. We seldom find out the cause at once. Then it is necessary to stabilize the dispersion of each of operations in the manufacturing line at first. Through the improvement cycle, we can reduce the dispersion of quality operations that have influenced on.

Table 7. The matrix of given priority to elemental operations

\begin{tabular}{|c|c|c|c|}
\hline & \multicolumn{2}{|c|}{ Importance of elemental operations } \\
\hline & & High & Low \\
\hline \multirow[t]{2}{*}{$\begin{array}{l}\text { Operation } \\
\text { Standard }\end{array}$} & No observance & Do observation & $\begin{array}{l}\text { Simplify the operation } \\
\text { standard }\end{array}$ \\
\hline & Observance & Reduce dispersion & $\begin{array}{l}\text { Permission of } \\
\text { dispersion }\end{array}$ \\
\hline \multicolumn{2}{|c|}{ No operation standard } & $\begin{array}{l}\text { Decide operation standard and } \\
\text { reduce dispersion }\end{array}$ & $\begin{array}{l}\text { Permission of } \\
\text { dispersion }\end{array}$ \\
\hline
\end{tabular}

\subsection{S6: Tool for "Decision again"}

In worrying about the quality problems, we will take the priority to the standard of elemental operations, and choose an operation that should be standardized again from some elemental operations by using the systematic chart of sub-material items. At first, we select the most important process by checking inspection items by using QC flow chart. If we find uninspected items or unobserved items though the observation by the operators, we will give a higher priority to them. If not, we should select the process composed of most dispersed one. Secondly, we select the most important elemental operation from selected process by constructing the matrix. S6 is used as follow.

- Make the factor chart for the quality characteristics composed of unit operations.

- Press the most important process by checking inspection items in QC flow chart or observation of operator in operation.

- Select the most important process by checking inspection items by using QC flow chart.

- Select the most important elemental operation from selected process by making the matrix.

Suppose that there are many factors have influence on the production. S6 is the systematically method of giving priority to decision operation standard again. We should take measures about meet them as Table 7.

\subsection{S7: Tool for "Evaluation"}

Finally, we proceed to the evaluation step that can find out the weak point of operation standardization, which is a relatively weak step of operation standardization compared with others. We express the evaluation tool $\mathrm{S} 7$ by a radar chart. We can understand weak step at a glance. S7 is used as follows

- Decide levels and contents of evaluation of operation standardization every step. We may decide them independently.

- Judge the step of operation standardization. 
- Paper the result of evaluation on the wall in manufacturing line, and operators understand the weak point of the operation standardization. Then we can connect with the improvement of a constitution in each section.

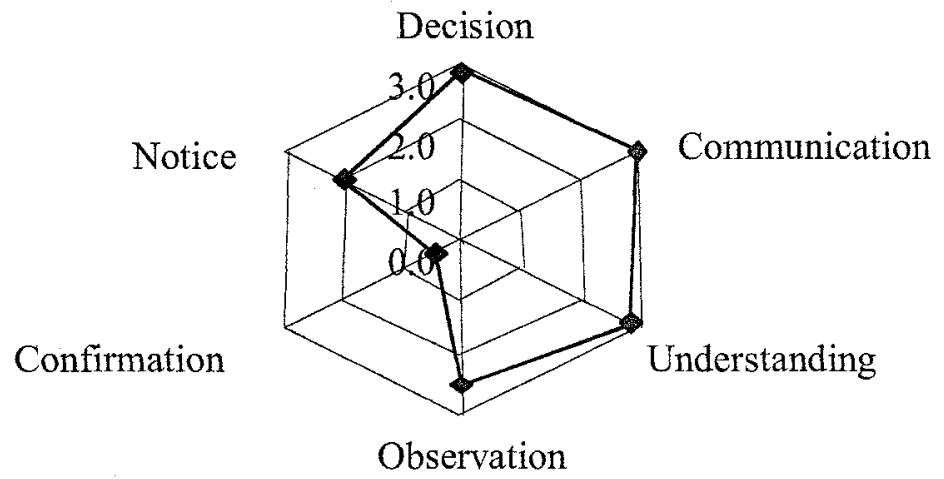

Figure 2. Evaluation the steps of operation standardization

\section{CASE STUDY}

We have used the proposed OS7 to the case of a semiconductor communication company. We have observed the time to the steady rate in quality to confirm the effectiveness of OS7 by comparing before and after the improvement. Many technicians noticed the cause of quality problem slightly, and they knew the three inferior modes (Table8), but they did not notice the cause of occurrence. So they tried to change the condition of machines many times, not reducing dispersion of operations in manufacturing line, however, there is no sign of improvement even after six months. It was a problem a group of technicians where the leader of the group was not interested in operation dispersion.

In the design cycle, we subjected to more fluently inferior modes of crack and flaw, caused by operation. The other technicians thought that it was caused by the condition of machines. We decided 33 operation standards again to reduce dispersion of these modes, using S1, and it took eight days, and to communicate them to all operators how dispersion of every elemental operations is with their rank, using S2. And we checked the observance of the operators to keep operation with a steady rate, using S3. For example, we prepared the visual operation standard and the tool for cutting to easy operation. Next, superintendents checked the observance of the operators in manufacturing line once a week, using S4. The rate of observance of operation standard rose up to $84 \%$.

In the improvement cycle, we tried to reduce the dispersion of elemental operations many times, using S5 and S6. We could extract 23 operator's know-how beyond expression in visual operation standard in this process.

In total, in the efforts of using OS7, we could reduce dispersion elemental operations and improved the production from $29 \%$ to $63 \%$ in average. Table 9 shows the comparison of before and after improvement in operation standard. 
Table 8. Comparison of before and after improvement of manufacturing index

\begin{tabular}{|l|l|l|l|l|}
\hline \multicolumn{2}{|c|}{ Before Improvement } & \multicolumn{2}{c|}{ After Improvement } \\
\hline Period & Six months & \multicolumn{2}{|l|}{ Three months } \\
\hline $\begin{array}{l}\text { The yield of } \\
\text { Product }\end{array}$ & $29 \%$ in average & $63 \%$ in average \\
\hline $\begin{array}{l}\text { Inferior goods } \\
\text { mode }\end{array}$ & Item & $\begin{array}{l}\text { The cause of } \\
\text { occurrence }\end{array}$ & Item & $\begin{array}{l}\text { The cause of } \\
\text { occurrence }\end{array}$ \\
\cline { 2 - 4 } & Crack: $17 \%$ & Mainly Operation & $\begin{array}{l}\text { Temperature: } \\
8 \%\end{array}$ & Mainly Machine \\
\cline { 2 - 5 } & Flaw: $15 \%$ & Crack: $2 \%$ & Operation \\
\cline { 2 - 5 } & $\begin{array}{l}\text { Temperature: } \\
12 \%\end{array}$ & Mainly Machine & Flaw: $1 \%$ & \\
\hline & Others: $2 \%$ & & Others: $1 \%$ & \\
\hline
\end{tabular}

Table 9. Comparison of before and after improvement in operation standard

\begin{tabular}{|c|c|c|c|c|}
\hline \multirow[t]{2}{*}{ Step } & \multicolumn{2}{|c|}{ Before Improvement } & \multicolumn{2}{|c|}{ After Improvement } \\
\hline & Content & & Content & \\
\hline Decision & $\begin{array}{l}\text { Element operations: } \\
23 \\
\text { Unit operations: } 6 \\
\text { (Stuffs decided } \\
\text { operation standard } \\
\text { only) }\end{array}$ & 28 days & $\begin{array}{l}\text { Element operations: } \\
56 \\
\text { Unit operation: } 6 \\
\text { (Stuffs and operator) }\end{array}$ & 8 days \\
\hline $\begin{array}{l}\text { Communicatio } \\
\mathrm{n} \text { and } \\
\text { understanding }\end{array}$ & $\begin{array}{l}\text { From two } \\
\text { technicians to only } \\
\text { one group leader }\end{array}$ & 1 day & $\begin{array}{l}\text { From two technicians } \\
\text { to all operators }\end{array}$ & 12 days \\
\hline Observance & $\begin{array}{l}\text { A Little operation } \\
\text { standard only }\end{array}$ & $\begin{array}{l}\text { A little } \\
\text { check }\end{array}$ & $\begin{array}{l}\text { Prepared tooled in } \\
\text { addition to operation } \\
\text { standard }\end{array}$ & $\begin{array}{l}\text { Total } 72 \\
\text { days }\end{array}$ \\
\hline Supervision & No check $\rightarrow 60 \%$ & $\begin{array}{l}\text { Total } 4 \\
\text { days }\end{array}$ & $60 \% \rightarrow 84 \%$ & $\begin{array}{l}\text { Total } 27 \\
\text { days }\end{array}$ \\
\hline Notice & Stuff only & $\begin{array}{l}2 \text { know- } \\
\text { how }\end{array}$ & $\begin{array}{l}\text { All operator and some } \\
\text { technicians }\end{array}$ & $\begin{array}{l}\text { Total } 23 \\
\text { know-how }\end{array}$ \\
\hline Decision again & Not Try & $\square$ & $\begin{array}{l}\text { Focus the subject of } \\
\text { improvement of } \\
\text { elemental operation } \\
\text { standard }\end{array}$ & $\begin{array}{l}\text { Total } 14 \\
\text { days }\end{array}$ \\
\hline Evaluation & Not Try & $\square$ & $\begin{array}{l}\text { Go to Supervision } \\
\text { step }\end{array}$ & Total 5 days \\
\hline
\end{tabular}

\section{CONCLUSION}

We have proposed the seven tools of operation standardization (OS7) to effectively establish the mass-production of a new product. We have suggested that we should divide process of operation standard into seven steps, that is, decision, communication and understanding, observance, supervision, notice, decision again, and evaluation. The proposed systematic seven tools of operation standardization (OS7) corresponding to these steps effectively prevent the quality problems at the 
implementation of mass production of a new product. OS7 enable us to realize massproduction of a new product and stabilize a product quality much more quickly. Note that OS7 is not a completed tool and should be reformed as operators can use it easily in production line.

\section{REFERENCES}

Fukuda, R (1997) Building Organizational Fitness: Management Methodology for Transformation and Strategic Advantage. Productivity Press Inc.

Sugitani, K (2000) The study of operation standardization for mass production of a new product (I). Proceedings of the Japanese Society For Quality Control (in Japanese)

Sugitani, K (2001) The study of operation standardization for mass production of a new product (II). Proceedings of the Japanese Society For Quality Control (in Japanese)

Sugitani, K (2002) The study of operation standardization for mass production of a new product (III). Proceedings of the Japanese Society For Quality Control (in Japanese)

Sugitani, K (2004) The study of operation standardization for mass production of a new product (IV). Proceedings of the Japanese Society For Quality Control (in Japanese)

Sumitomo Electric Industry (1993) Practical use of cause and effect diagram by card in standardization and quality control. No. 5-4200 (in Japanese) 